\title{
Cultural and Historical Development of Everyday Life as a National Security Guarantee
}

Anna Sergeevna Frolova ${ }^{1}$

\author{
Svetlana Aslanovna Lyausheva²
}

Eugenia Sergeevna Sagalaeva ${ }^{3}$

Sergey Ivanovich Samygin ${ }^{4}$

Yury Grigorievich Volkov 5

\begin{abstract}
1 Institute of Sociology and Regional Studies, Southern Federal University, Rostov-on-Don, Russian Federation ${ }^{2}$ Adyghe State University (Department of Philosophy and Sociology), Maikop, Russian Federation ${ }^{3}$ Institute of Law, North-Caucasus Federal University, Stavropol, Russian Federation

${ }^{4}$ Rostov State University of Economics (RSUE), Rostov-on-Don, Russian Federation

${ }^{5}$ Institute of Sociology and Regional Studies, Southern Federal University, Rostov-on-Don, Russian Federation Correspondence: Yury Grigorievich Volkov, 160 Pushkinskaya St., Rostov-on-Don, 344005, Russian Federation
\end{abstract}

Doi:10.5901/mjss.2015.v6n5s4p417

\section{Abstract}

In the modern Russian society everyday life approves itself as an important fragment of social reality. The ideological everyday life discourse actualization is driven by the importance and efficiency of its heuristic potential under the conditions when the situation dictates the requirement of new understanding of habitual long-held categories and approaches, and the processes setting the horizon of the possible changes move to the forefront. The article reveals the notional format of cultural and historical development of everyday life that allows emphasizing issues and plots of the analysis which is connected with application of logically linked procedures broadening the opportunities of interpretation of different plots and aspects of social processes and pragmatist practices. Study of specific character of everyday life cultural and historical development process will enable to understand the essence of the processes happening in the society, reveal social and cultural shifts and develop an optimal strategy to provide social stability, resist inner threats to national security rooted in the axiological content of a lifeworld and everyday life.

Keywords: ideology, everyday life, the past, history, social and historical development, national security

\section{Introduction}

Grounds and conditions of manifestation and development of everyday life are connected with multidimensionality of social and historical processes both in the parameters of their real existence and in the coordinates of their theoretical interpretation, which emphasizes the issues and plots of analytical activity and application of logical procedures and notions capable of expanding the space of interpretation of various aspects of social and cultural development as well as pragmatist practices. By virtue of essences, meanings and symbols being relevant for understanding of a definite cultural and historical space, reflexive perception and construction of social and cultural reality is implemented in the processes of its historical development. Ontology of cultural and historical development of everyday life in the historical reality in Russia has always manifested itself when the political elite faced the necessity to strengthen the impact on the collective consciousness. The Russian society has been in a state of permanent transformation for a long time, a social and cultural shift is happening; the necessity of notional, axiological and ideological denotation of everyday life is actualizing. And this is directly connected with the ability of the society to overcome internal contradictions, to provide stability and development and therefore with provision of national security.

\section{Literature Review}

In order to study the phenomenon of everyday life being a complicated and comprehensive problem of social philosophy, first of all it is necessary to refer to the works by E. Husserl (1913), who was the first to elaborate phenomenological and 
hermeneutical approaches to understanding of the this phenomenon. Husserl's social phenomenology proceeds from the fact that everyday life is a foundation of social existence and the world of common sense. E. Husserl and A. Schutz were the first to introduce a notion "lifeworld" into the scientific use; this notion became one of the first constructs to describe everyday life space (Ruggerone, 2012).

It should be noted that everyday life also occurred in the field of scientific and theoretical reflection of such researchers as M. Weber (1999), L. Wittgenstein (1980), H. G. Gadamer (2004), M. Heidegger (2010).

In the last decades of the XX century everyday life manifested itself as a specific subject of social and humanitarian disciplines; various scientific schools studying this phenomenon were formed. Thus, one may point out a German school "Everyday Life History" (founded by H. Medik and A. Lüdtke), "Microhistory" school in Italy (founded by K. Ginzburg, J. Levi, E. Grendy) (Smirnov, 2013).

When it comes to relation between everyday life and ideology, without doubt one should not leave unnoticed the basic concepts by E. Durkheim, K. Mannheim 1950) considering the ideology phenomenon as a result of a cohabitation of people, their natural and social and historical circumstances. E. Durkheim interpreted worldview forms as a key factor consolidating the social system (Durkheim, 1982).

A philosopher, A. V. Smirnov, while revealing historical and methodological aspects of everyday life conceptualization, draws attention to the circumstance that acquisition of a status of an independent object of social and humanitarian disciplines by everyday life has caused destruction of theoretical and methodological, as well as thematic borders in the cognitive space of traditional scientific knowledge (Smirnov, 2013).

N. L. Novikova proceeds from the premise that everyday life reveals the ontological nature of the culture as an "existence on the edge of eternity, as a breakthrough into the sphere of the absolute, a breakthrough that had found an extremely adequate form of expression, not rupturing with historical time, but dominating over it, conquering the time through language, customs, traditions, rituals" (Novikova, 2003).

I. T. Kasavin supposes that everyday life as a problem of philosophy stems from the estimate of all three parameters composing it; they are everyday reality, everyday consciousness (knowledge) and "philosophy of common sense". But different philosophical traditions trace various objects in the phenomenon of everyday life, considering everyday life through various treatments of central philosophic categories (Kasavin, 2003).

For A. Schutz everyday life serves as a product of interaction between a person and the world. A. Schutz considers everyday life as a paramount reality in comparison to which other spheres are represented as quasi-realities (Schutz, 1988).

\section{Methodology}

The basis of the theoretical and methodological construct is represented by statements and conclusions of the works by P. Bourdieu (1992) and Y. Habermas that present fundamental statements on individualization of lifeworld as everyday life. An equally important role was also played by phenomenological theory of lifeworld elaborated by $\mathrm{E}$. Husserl; procedural theory of everyday life by G. Gadamer; systemic theory of things by J. Baudrillard (Kellner, 1994).

One can distinguish the following approaches being the basis for the author's theoretical and research construct enabling to implement understanding of ideological everyday life: a) Process approach; b) Ideology and axiological structure of everyday consciousness; $c$ ) The paradigm of symbolic politics and symbolic exchange; d) Phenomenological anthropology and phenomenological psychology. This comprehensive approach makes it possible to outline the semantic contours of the problem study field and develop a concept of ideological everyday life, as well as reveal and analyze the processes for reproduction of ideological everyday life in the media space.

Depending on their aims the leaders direct their people in the right direction. A crowd is the managed energy of the leaders. The crowd is unstable and hardly controllable. The crowd has not got basic notions, ideas, and ideals. Everyday life structure changes (Smirnov, 2013).

Huge energy of the crowd discharges on the object against which it is directed. The crowd does not think about the shift, it is looking for an enemy and personifies all its misfortunes with this enemy. The crowd cannot experience permanent of long-term fancies. It has always got a temporary interest and temporary love, and likewise temporary hatred.

Everyday life is an area concealed from an individual, it is situated in the shadow, and it is somehow hidden in the "gloomy sphere of the habitual, in an unconscious kinetics of daily repeated motions". At those moments when the human consciousness, suddenly awaken from routine, is trying to establish the dynamics of those motions, its principles seemed to be strange, alien, only vaguely resembling intimate habits of our body. Reflexivity makes changes in the quality of such a motion, in its kinetics. At the moment of reflection on everyday life, its outlines are changing, too. Trying to fix everyday 
life, having catalogued its repertoire and structured the relations between its elements, we are destroying its nature, though based on the repetition but fluctuating in its substance, we put a dot in place of elision marks (Kalinin, 2007).

In the epochs of civilizational collapses a hidden principium of culture becomes uncovered, in other words, that multiform system of habitual life practices, attitudes and values, which are stricken at. Aspiring to revive the disintegrated "link of the times", a person tries to reconstruct the traditionally established common practice. He aspires to revive his existence in the totality of his personal and social interactions and links, which include, for example: a) Friendly, love, family, professional and partner relations; b) Everyday practices, life style, habitat c) Sets of beliefs, moral and ethical as well as behavioral matrices; d) The border between public and private spheres of life; e) Individual and collective memory; f) Forms of social stratification and mobility; g) Expressed individual and collective identity; h) Diverse varieties of intellectual and artistic reflection (Prokhorova, 2012).

Social philosophers proceed from the fact that everyday life is a fragment of a social reality, a form of its existence. Any time creates its perceptions about natural content of everyday life. Determining the conceptual format of cultural and historical development of everyday life, T. M. Tuzova justly considers that it is difficult to overestimate the importance and urgency of the issue of constitutive activity of the natural reflection , structures and contents of everyday experience; this can be testified by a great number of investigations dedicated to everyday life, ordinary experience, ordinary consciousness, everyday speech and human behavior, everyday life culture (Tuzova, 2001).

Through implications, symbols and meanings inherent in a definite cultural and historical context, cognition and construction of reality occur during its historical development.

In the course of interaction of actors in everyday life existence former social forms are not only arrogated and reproduced, but also modified. Such actions, being historical, are implemented and objectified in some external for subjects space which somehow "presses" with its givenness on the existing, but at the same time opens future coordinates to this existing (Bezotosnyi, 2011).

B. V. Dubin, a social philosopher and sociologist, writes about symbolic construction of social and political reality in the contemporary Russia, about bearing symbols and figures distributed through communicative channels (Dubin, 2011). All this is broadly applicable to the estimate of the processes of everyday life cultural and historical development.

In Imperial Russia origination of mythical realities was inevitably connected with the autocracy as a system of power relations and its self-presentation through verbal, artistic, and behavioral images. An individual mythological and symbolic language was formed, including coronations, solemn entries, parades, court receptions and meetings with the help of which the autocracy and the ruling class communicated with the masses.

This "ideological language" or "power scenario", as it is called by R. Wortman, was changing from one reign to another and corresponded to those historical challenges confronting another representative of the Romanovs' royal house and which were to be solved. Staging of myths containing values of monarchical power was transformed into peculiar political rituals, being so necessary to demonstrate the greatness and the legitimacy of the emperor and the ruling elite (Wortman, 2004).

In the Soviet period similar political rituals preserved their value. But, at the same time, everyday life was exposed to harassment, and the Soviet culture itself required to struggle with private life. The official Soviet culture appreciated everyday life not really high. Everything referring to household life was seen as "second-rate", "peripheral", everyday life was considered by the official culture at the best case as an addition to public life.

Soviet people were brought up in the spirit of asceticism, contempt for "petty bourgeoisie", life "for themselves". Private existence of a person was pushed aside by the state to the life outskirts. The natural result was derogation of a private sphere of existence starting from the lack of food products and fast moving consumer goods, that is fashionable clothes, furniture and other things making the existence simpler and more beautiful, and ending with disrespect to the space and time of everyday life (the absence of a notion of private house and private property immunity, state ownership of housing funds and lands, all-hands-ahoy traditions, rapid improvement events in off-hours, involuntary Saturday works, appearance of two days-off only in the middle of 1960-ies).

It is no coincidence that the aims of life existence, according to the Soviet ideology, were to bring maximum benefit to the state and society and not to be engaged in arrangement of a private life. Authorities and official culture were struggling with everyday life as it was a sphere relatively free from the state influence.

Making it possible for people to live with their own concerns, keep their household, take care after their families, build their own existence, everyday life served as a refuge from the regime and its ideology, since it allowed the individuals disposing themselves relatively freely. Moreover, holding exhibitions of non-official art, distribution of selfpublished literature, non-censored tape recordings were connected with everyday life space (Vorobyova, 2014).

J. Hellbek states that in the Soviet period the ideology convinced people in the necessity to participate in a great "initiative", hiding the truth about their constrained state. In these circumstances, an essential part of the population was 
actively participating in the Bolshevist project (Hellbek).

According to B. Waldenfels, everyday life, the function of theories of everyday life and definite practical actions can be thematized by various means, for example, proceeding from the subject, from objectively existing world of bodies, from social relations, from the process of language communication or from actions becoming automatic.

Proceeding form the issue of a specific rationality of everyday life, that is from those things that are personified by semantic, regularly repeated, rational and transparent interrelations exiting in various spheres and styles of rationality, it can be concluded that permanently changing forms of rationality along with particular forms of irrationality rather than one universal form of rationality confront the forms of irrationality (Waldenfels, 1991).

A theme of common sense can be frequently met in a semantic format of cultural and historical development of everyday life.

Revealing the semantic format and fixed semantics of cultural and historical development of everyday life, a social philosopher, R. A. Migurenko, characterizes everyday life through the categories of "reality", "everyday consciousness", "truth of common sense", and "natural language". According to the researcher, in this case a human individual not capable of independent reflection imagines the world of everyday life as a primary and autonomous reality existing somewhat on its own (Migurenko, 2011).

The ontology of cultural and historical development of everyday life in the space of the Russian historical reality is inevitably conditioned by the expressed social instability, institutional weakness of the system. However, under the conditions of the today's global world everyday life preserves its function of a stability shelter in an increasingly lesser degree.

Flexibility and mobility inherent in everyday life lag behind rapid changes of information, material, cultural and social spheres (Zarubina, 2011). Everyday life is increasingly transforming from the sphere of stability into the sphere of risk originating from its stable structures that earlier had provided security, Firstly, the conditions of modern life require mobility and dynamism, ability to rapid changes, reconstruction, innovations affecting all levels of social existence (Frolova \& Volkov, 2015), including everyday life. Risks created by new production technologies and their global mobility force a modern person to rapidly change the consumer habits, morals and manners, as well as the place of work, residence, if possible.

People can defend themselves from modern risks only if they are able to effectively estimate probability and consequences of these risks and if they have sufficient social, cultural and economic resources in order to "quit" the dangerous environment quickly. The advantages are received by those who are able to be initiators of innovations. On the contrary, the aspiration to save the existence conditions unchanged, continue to rely on existing structures under rapidly changing external conditions is fraught with additional risks and losses.

Secondly, constant alterations, mobility and dynamism are obtruded as an attribute of contemporaneity. Adherence to customs, conventional samples, fidelity to traditions is interpreted as attributes of "obsolescence". That is why those who do not want to risk their symbolic capital shall strive to keep pace with the rapid changes not only in fashion, but in information, professional skills, market conditions (Zarubina, 2011).

Everyday life begins to be recognized as communicative system reflecting objective and subjective, available and empiric as well as constructive levels of sociocultural reality. However, in the modern consumer society everyday life cannot be regulated by self-reproducing stable samples of reality interpretation, behavior stereotypes and relation structures. It is continuously exposed to deconstruction on the part of social institutions providing construction and introduction of new myths, first of all, on the part of mass media, advertising and mass culture.

In this regard freedom in the modern Russian society has lost the feeling of novelty. Freedom as a value, as a practice and choice has credit neither in the political elite nor in masses. People began to prefer illusions of "calmness", "stability", "strong state", "managed democracy", "justice" to freedom. When the society has undergone spiritual degradation, reverted childish unconsciousness and irresponsibility and sunk into infantile dreams, perceptions on liberalism and conservatism have been degenerated simultaneously. A liberalist is perceived now as a cosmopolitan, a selfish person and a hedonist.

A particular role in everyday life deconstruction begins to belong to consumption globalization. Global companies' brands are consumed as symbols of involvement into the advanced and progressive, but at the same time alien standards intrude through them into everyday life of different world regions, pushing out habitual norms, destroying morals and manners that have been forming for ages, and life patterns (Zarubina, 2011).

\section{Conclusions}

1) Conditions of everyday life are connected with multidimensional space of social and historical development, 
both in the context of its real existence and within the coordinates of theoretical reflection, which compels to emphasize the whole range of issues and plots, including those connected with application of logical procedures, methods and categories contributing to expand opportunities of analytical understanding of various aspects of social development and pragmatist practices of social actors.

2) Each stage of everyday life development forms own perceptions on its content. Cognition and construction of sociocultural reality occurs in the processes of its historical development through senses, symbols and meanings correlated with any definite cultural and historical context. A semantic format of everyday life cultural and historical development is conditioned by the fact that own ups and downs take place in the development of a human community, as well as in the life of a definite socium or individual, and the periods of stable and progressive development intersperse with cataclysms and catastrophes, periods of instability, times of social and spiritual upheavals.

3) In the semantic format of cultural and historical development everyday life can be defined as reality, habitual consciousness, as a region of generation of common sense truths. Everyday life destination consists in establishing stable correlation between reality and knowledge about it, knowledge and language, language and reality.

4) Ontology of cultural and historical development of everyday life has always manifested in the historical reality of Russia with clearly expressed social unrest and weakness of institutional system, underdevelopment of institutional traditions, when it became necessary for the elite to strengthen the influence on one or another segments of mass public consciousness. Everyday life began to be understood as a communicative system reflecting objective and subjective, available and empiric as well as constructive levels of sociocultural reality.

5) In the modern consumer society everyday life cannot be regulated by self-reproducing samples of reality interpretation, behavior stereotypes and relation structures. It is continuously exposed to deconstruction on the part of social institutions providing construction and introduction of new myths through mass media, advertising and mass culture. A particular role in everyday life deconstruction begins to belong to globalization of consumption that penetrates all levels of social existence. As a result, axiological objectives become lost, which would allow give sense to the society development, provide its integrity and spiritual security. The space of everyday life is inseparably associated with the issue of national security because all social, economic and political transformations are embodied precisely in this space.

\section{Acknowledgement}

The article is implemented within the framework of implementation of Southern Federal University internal grant No. 213.01-07-2014/15ПЧВГ "Threat to National Security in the Context of Geopolitical Competiveness and Model of Aggressive and Hostile Youth Behavior".

\section{References}

Bourdieu, P., \&Wacquant, L. J. D. (1992). An Invitation to Reflexive Sociology. Chicago and London: Univ. of Chicago Press.

Durkheim, É. (1982). The Rules of Sociological Method. New York, London, Toronto, Sydney: The Free Press. Retrieved from http://comparsociology.com/wp-content/uploads/2013/02/Emile-Durkheim-Rules-of-Sociological-Method-1982.pdf

Frolova, A. S. \& Volkov, Y. G. (2015). Ideological Dimension of the Network Society and the Ideology of Global Humanism. Mediterranean Journal of Social Sciences, 6(3), S3.

Gadamer, H. G. (2004). Truth and method. Chicago: Continuum.

Heidegger, M. (2010). Being and Time. Albaniae: State University of New York Press.

Husserl, E. (1913). Ideen zu einer reinen Phänomenologie und phänomenologischen Philosophie: Buch 1, Allgemeine Einführung in die reine Phänomenologie. Retrieved from http://www.freidok.uni-freiburg.de/volltexte/5973/

Kellner, D. (Ed.). (1994). Jean Baudrillard: A Critical Reader. Oxford: Basil Blackwell.

Mannhaeim, K. (1950). Freedom, power and democratic planning. London.

Ruggerone, L. (2013). Science and Life-World: Husserl, Schutz, Garfinkel. Human Studies, 36(2).

Thurman, R. A. F. (1980). Philosophical Nonegocentrism in Wittgenstein and Candrakirti in Their Treatment of the Private Language Problem. Philosophy East and West, 30(3).

Weber, M. (1999). Sociological Writings. Retrieved from https://www.marxists.org/reference/subject/philosophy/works/ge/weber.htm

Bezotosnyi, I. A. (2011). Positive Image of Russia: Construction and Representation of Symbolic Social Reality. Rostov-on-Don.

Waldenfels, B. (1991). Everydayness as Melting Cup of Rationality. Socio-Logos (pp. 40-41).

Vorobyova, M. V. (2014). Soviet Existence: Cliché of Ideology and Reality. Retrieved from www.culturalnet.ru/

Glushchenko, I. Soviet Everyday Life through the Prism of Subtraction. Logos, 2(98), 156-166. 
Dubin, B. V. (2011). Russia of Zeros: Political Culture-Historical Memory—Everyday Life. M.: ROSSPEN.

Zarubina, N. N. (2011). Everyday life in the Context of Sociocultural Transformations of Russian Society. Public Sciences and Modernity, 4.

Kalinin, I. A. (2007). Everyday life "which is Always by your Side". Untouched Stock, 4(54).

Kasavin, I. T. (2003). Everyday life in the Context of Phenomenological Sociology. Sociemy, 9.

Migurenko, R. A. (2011). Everyday life, Common Sense and Consciousness Issue. Philosophy. Sociology. Political Science, 2(14), 114121.

Prokhorova, I. (2012). Caesar's Iron Month. New Literature Review, 116.

Novikova, N. L. (2003). Everyday life as a Phenomenon of Culture. Saransk: Mordovia University Press.

Smirnov, S. Education of a Person in Everyday Life Structures. Retrieved from http://www.archipelag.ru/

Tuzova, T. M. (2001). Specific Character of Philosophic Reflection. Mn.: Law and Economics.

Wortman, R. (2004). Rulers and Judges. Development of Law Consciousness in Imperial Russia. M.: Novoye Literaturnoye Obozreniye. Hellbek, J. (2010). Everyday life Ideology: Life during Stalinism. Retrieved from http://polit.ru/2010/11/24/

Schutz, A. (1988). Structure of Everyday Life Thinking. Sots/s, 2, 130. 